\title{
Racial and Socioeconomic Disparities in Hip Fracture Care
}

Christopher J. Dy, MD, MPH, Joseph M. Lane, MD, Ting Jung Pan, MPH, Michael L. Parks, MD, and Stephen Lyman, PhD Investigation performed at the Hospital for Special Surgery, New York, NY

Background: Despite declines in both the incidence of and mortality following hip fracture, there are racial and socioeconomic disparities in treatment access and outcomes. We evaluated the presence and implications of disparities in delivery of care, hypothesizing that race and community socioeconomic characteristics would influence quality of care for patients with a hip fracture.

Methods: We collected data from the New York State Department of Health Statewide Planning and Research Cooperative System (SPARCS), which prospectively captures information on all discharges from nonfederal acute-care hospitals in New York State. Records for 197,290 New York State residents who underwent surgery for a hip fracture between 1998 and 2010 in New York State were identified from SPARCS using International Classification of Diseases, Ninth Revision, Clinical Modification (ICD-9-CM) codes. Multivariable regression models were used to evaluate the association of patient characteristics, social deprivation, and hospital/surgeon volume with time from admission to surgery, in-hospital complications, readmission, and 1-year mortality.

Results: After adjusting for patient and surgery characteristics, hospital/surgeon volume, social deprivation, and other variables, black patients were at greater risk for delayed surgery (odds ratio $[\mathrm{OR}]=1.49 ; 95 \%$ confidence interval $[\mathrm{Cl}]=1.42$, 1.57), a reoperation (hazard ratio $[\mathrm{HR}]=1.21 ; \mathrm{Cl}=1.11,1.32$ ), readmission $(\mathrm{OR}=1.17 ; \mathrm{Cl}=1.11,1.22$ ), and 1-year mortality $(\mathrm{HR}=1.13 ; \mathrm{Cl}=1.07,1.21)$ than white patients. Subgroup analyses showed a greater risk for delayed surgery for black and Asian patients compared with white patients, regardless of social deprivation. Additionally, there was a greater risk for readmission for black patients compared with white patients, regardless of social deprivation. Compared with Medicare patients, Medicaid patients were at increased risk for delayed surgery $(\mathrm{OR}=1.17 ; \mathrm{Cl}=1.10,1.24)$ whereas privately insured patients were at decreased risk for delayed surgery $(\mathrm{OR}=0.77 ; \mathrm{Cl}=0.74,0.81)$, readmission $(\mathrm{OR}=0.77 ; \mathrm{Cl}=0.74,0.81)$, complications $(\mathrm{OR}=0.80 ; \mathrm{Cl}=0.77,0.84)$, and 1-year mortality $(\mathrm{HR}=0.80 ; \mathrm{Cl}=0.75,0.85)$.

Conclusions: There are race and insurance-based disparities in delivery of care for patients with hip fracture, some of which persist after adjusting for social deprivation. In addition to investigation into reasons contributing to disparities, targeted interventions should be developed to mitigate effects of disparities on patients at greatest risk.

Level of Evidence: Prognostic Level III. See Instructions for Authors for a complete description of levels of evidence.

Peer review: This article was reviewed by the Editor-in-Chief and one Deputy Editor, and it underwent blinded review by two or more outside experts. It was also reviewed by an expert in methodology and statistics. The Deputy Editor reviewed each revision of the article, and it underwent a final review by the Editor-in-Chief prior to publication. Final corrections and clarifications occurred during one or more exchanges between the author(s) and copyeditors.

$\mathrm{T}$

1 he annual costs associated with caring for patients with hip fractures in the United States are projected to rise to USD 25 billion by $2025^{1}$. Given this substantial cost

burden and the devastating effects of the injury, improvements in the quality and value of hip fracture care are attractive to both policymakers and health-care providers. Despite national

Disclosure: C.J.D. received funding from the National Institute of Arthritis and Musculoskeletal and Skin Diseases (NIAMS; Grant T32-AR07281) and an Orthopaedic Research and Education Foundation Young Investigator grant. Each author certifies that he or she has no commercial associations (e.g., consultancies, stock ownership, equity interest, patent/licensing arrangements, etc.) that might pose a conflict of interest in connection with the submitted article. On the Disclosure of Potential Conflicts of Interest forms, which are provided with the online version of the article, one or more of the authors checked "yes" to indicate that the author had a relevant financial relationship in the biomedical arena outside the submitted work and "yes" to indicate that the author had other relationships or activities that could be perceived to influence, or have the potential to influence, what was written in this work. 
TABLE I Patient and Hospital Characteristics $(\mathrm{N}=197,290)$

\begin{tabular}{|c|c|}
\hline Characteristics & No. (\%) \\
\hline \multicolumn{2}{|l|}{ Patient Characteristics } \\
\hline \multicolumn{2}{|l|}{ Age group } \\
\hline$<65 \mathrm{yr}$ & 21,967 (11.1\%) \\
\hline $65-75 y r$ & $29,683(15.1 \%)$ \\
\hline $76-85 \mathrm{yr}$ & $75,453(38.2 \%)$ \\
\hline$>85 \mathrm{yr}$ & 70,187 (35.6\%) \\
\hline \multicolumn{2}{|l|}{ Sex } \\
\hline Male & $52,916(26.8 \%)$ \\
\hline Female & $144,374(73.2 \%)$ \\
\hline \multicolumn{2}{|l|}{ Race } \\
\hline White & $166,782(84.5 \%)$ \\
\hline Black & $9,457(4.8 \%)$ \\
\hline Asian & $3,252(1.7 \%)$ \\
\hline Other & $9,610(4.9 \%)$ \\
\hline Missing & $8,189(4.2 \%)$ \\
\hline $\begin{array}{l}\text { Osteoporosis diagnosis present } \\
\text { on admission }\end{array}$ & $32,178(16.3 \%)$ \\
\hline \multicolumn{2}{|l|}{ Deyo comorbidity index } \\
\hline 0 & $102,119(51.8 \%)$ \\
\hline 1 & $54,185(27.5 \%)$ \\
\hline 2 & $21,488(10.9 \%)$ \\
\hline 3 & 8,039 (4.1\%) \\
\hline$\geq 4$ & $11,459(5.8 \%)$ \\
\hline \multicolumn{2}{|l|}{ Insurance type } \\
\hline Medicare & $163,643(83.0 \%)$ \\
\hline Medicaid & 7,673 (3.9\%) \\
\hline Private & $17,423(8.8 \%)$ \\
\hline Workers' Compensation & $1,854(0.9 \%)$ \\
\hline No-fault & $3,275(1.7 \%)$ \\
\hline Other or uninsured & $3,422(1.7 \%)$ \\
\hline \multicolumn{2}{|l|}{ Type of hip fracture treatment } \\
\hline Total hip arthroplasty & $5,963(3.0 \%)$ \\
\hline Hip hemiarthroplasty & $56,865(28.8 \%)$ \\
\hline $\begin{array}{l}\text { Other (including open reduction } \\
\text { and internal fixation) }\end{array}$ & $134,462(68.2 \%)$ \\
\hline \multicolumn{2}{|l|}{ Characteristics of treating hospital } \\
\hline \multicolumn{2}{|l|}{ No. of beds } \\
\hline$<200$ & $40,382(20.5 \%)$ \\
\hline $200-299$ & 41,519 (21.0\%) \\
\hline 300-399 & 30,316 (15.4\%) \\
\hline $400-499$ & 27,940 (14.2\%) \\
\hline$\geq 500$ & $57,133(29.0 \%)$ \\
\hline \multicolumn{2}{|l|}{ Location of hospital } \\
\hline Urban & 171,467 (86.9\%) \\
\hline Rural & 25,823 (13.1\%) \\
\hline \multicolumn{2}{|l|}{ Teaching status } \\
\hline Teaching & 70,853 (35.9\%) \\
\hline Not teaching & 127,067 (64.4\%) \\
\hline
\end{tabular}

trends indicating declines in both the incidence of and associated mortality following hip fracture ${ }^{2,3}$, a growing body of evidence suggests that there are racial and socioeconomic disparities in treatment and outcomes of this condition ${ }^{4-6}$. As our health-care system strives toward the consistent provision of high-quality, high-value care, these disparities must be better understood.

Studies from outside of the United States have demonstrated the influence of patient and community characteristics on the treatment and outcomes of hip fractures ${ }^{7,8}$. However, these relationships have not been yet clearly defined for patients in the United States. The unique considerations of American health care, such as the presence of a large government-based insurer in a multipayer fee-for-service environment, justify further investigation. Previous studies of potential racial and socioeconomic disparities in hip fracture outcomes in the United States have been largely limited to Medicare beneficiaries, with mortality as the lone outcome $\mathrm{e}^{10-12}$. Evaluation with metrics regarding multiple payers and additional outcomes is necessary to more fully characterize the extent of disparities in the care of patients with hip fractures.

In the current investigation, we used statewide administrative data from 1998 to 2010 to determine the presence and implications of disparities in delivery of care to patients with hip fractures. We hypothesized that race and community socioeconomic characteristics would influence the quality of care for patients with hip fractures, as measured by the timing of surgery, reoperations within 1 year, 90-day readmissions, 90-day complications, and 1-year in-hospital mortality.

\section{Materials and Methods}

\section{Study Population and Data Sources}

The New York State Department of Health Statewide Planning and Research 1 Cooperative System (SPARCS) prospectively captures information on all discharges from nonfederal acute-care hospitals in New York State. Records for 197,290 New York State residents who underwent surgery for a hip fracture between 1998 and 2010 in New York State were identified from SPARCS using International Classification of Diseases, Ninth Revision, Clinical Modification (ICD-9-CM) codes (see Appendix). To identify subsequent events, we searched records for 1 year following discharge. This data set has been used for prior investigations of orthopaedic health services, and the comprehensiveness of its procedure codes has been validated for total knee arthroplasty ${ }^{13}$.

\section{Definitions of Predictors}

Patient age, sex, race, comorbidities, presence of an osteoporosis diagnosis (based on ICD-9 diagnosis code) on admission, type of surgery (total hip arthroplasty, hip hemiarthroplasty, or internal fixation), and insurance status were considered potential patient-level predictors of outcomes after hip fracture treatment. Race was defined as white, black, Asian/Pacific Islander, or other. A comorbidity index was calculated using the Deyo modification of the Charlson Comorbidity Index ${ }^{14,15}$, which includes dementia as a component. Insurance status was defined as private, Medicare, Medicaid, Workers' Compensation, no-fault, or other/uninsured. On the basis of the same ICD-9-CM codes used for identification of the study cohort (see Appendix), hospital volume of hip fracture surgery was calculated for the 4 quarters before the quarter of the index surgery for each patient. The same process was used to determine the surgeon's annual volume of hip fracture surgery.

To estimate the socioeconomic status of the patient's surrounding community, we included the Area Deprivation Index ${ }^{16}$. This index is a validated geographic neighborhood-based measure of socioeconomic deprivation based on United States Census data. The number of hospitals within the patient's 


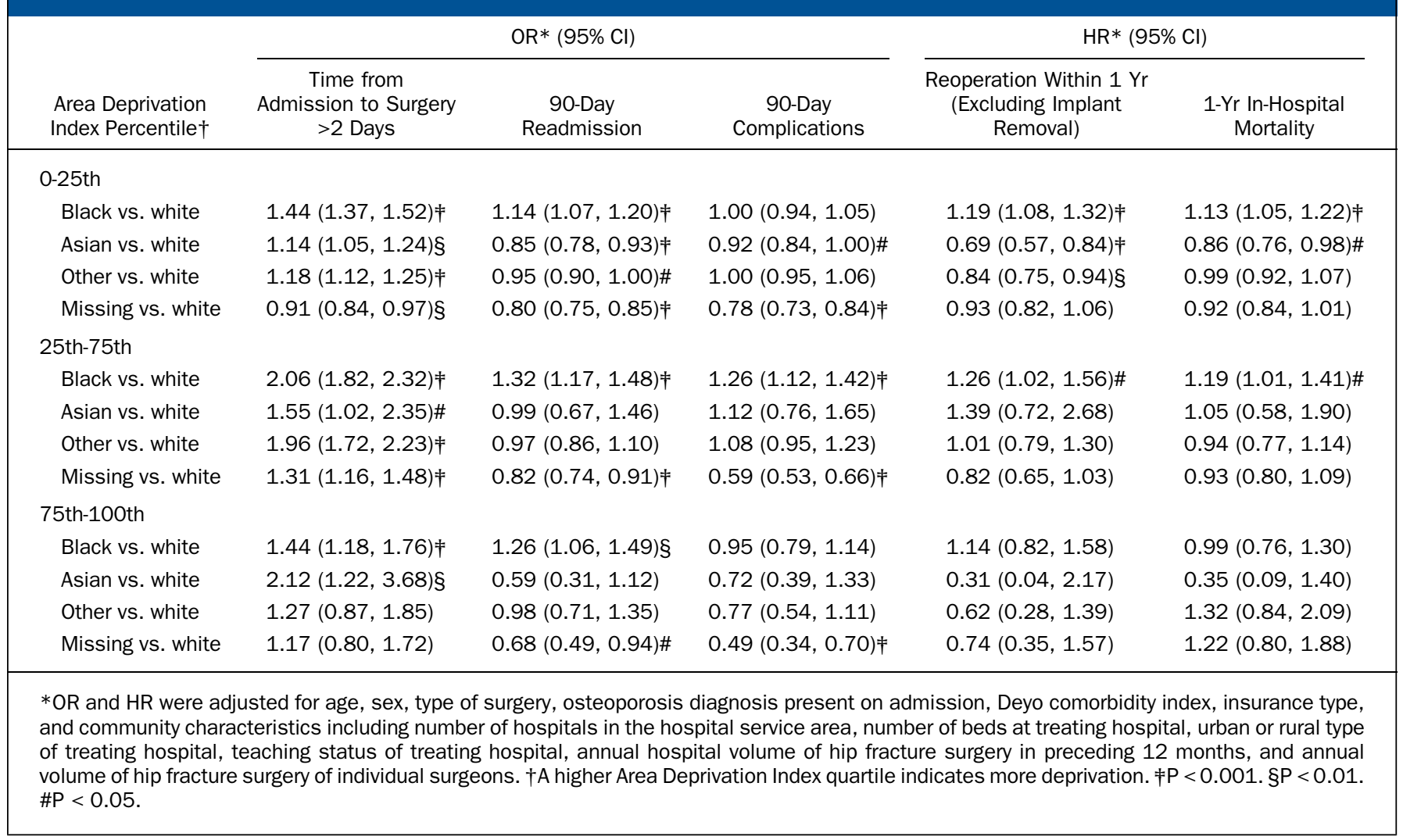

hospital service area (as defined by the Dartmouth Atlas of Health Care ${ }^{17}$ ) was derived from annual American Hospital Association survey data. The hospital was determined to be in either a rural or an urban community using the RuralUrban Commuting Area Codes ${ }^{18}$. Selected characteristics of the hospital (number of beds and teaching status) where the patient was treated were also recorded for the purpose of inclusion in the multivariable regression model.

\section{End Points of Analysis}

The timing of surgery was designated as either within or after 2 calendar days from the date of admission. The type and timing of subsequent procedures, complications within 90 days, readmission within 90 days, and in-hospital mortality within 1 year of discharge were recorded. Deaths that occurred outside of a hospital within New York State (such as at home or out of state) were not captured in this analysis. A subsequent procedure for removal of implants alone (without any additional procedures) was excluded as a reoperation because of its potentially elective nature. The following complications were recorded: acute myocardial infarction, congestive heart failure, cerebrovascular ischemia/stroke, pulmonary embolism/deep venous thrombosis, intracranial injury, burns, retained foreign object, air embolism, blood incompatibility, major bleeding, sepsis/septicemia/ shock, pressure ulcer, catheter-associated urinary tract infection, vascular catheterassociated infection, ileus, pneumonia, surgical site infection (including both periprosthetic and wound infections), hip dislocation, hip fracture, and mechanical complications (ICD-9-CM codes shown in the Appendix).

\section{Statistical Analyses}

Multivariable logistic regression models were used to evaluate the association of patient and community characteristics with time to surgery, readmission, complications, reoperations, and mortality while adjusting for surgery type, osteoporosis diagnosis on admission, number of hospitals within the patient's surrounding community, number of beds in the treating hospital, type of hospital (urban or rural), teaching status of hospital, and Area Deprivation Index ${ }^{16}$. All models included both hospital and surgeon volume, categorized by quartile and with the highest-volume quartile used as the reference group. Cox proportional hazards models with similar covariable adjustments were used for reoperations and 1-year mortality. For the reoperation model, any patients who died during the index hospital admission or within 1 year after the index surgery were censored. All eligible variables were included in the models. All analyses were performed using the SAS System for Windows 9.3 (SAS Institute).

\section{Subgroup Analyses}

To further examine the influence of socioeconomic characteristics on our outcomes of interest, we performed a series of subgroup analyses. On the basis of the Area Deprivation Index of their community, patients were stratified into the lowest Area Deprivation Index quartile (least deprived), the middle 2 quartiles, and the highest quartile (most deprived). Within these groups, the likelihood of experiencing a delay of $>2$ days before undergoing surgery, readmission within 90 days, complications, reoperations, and mortality were compared among racial groups (white, black, Asian, and other, with white as the reference group). For example, the risk of readmission was compared between black and white patients within the highest Area Deprivation Index quartile (most deprived). These multivariable regression analyses were adjusted for the same covariables included in the main analysis.

\section{Results}

There were 197,290 patients included in the study. The mean age (and standard deviation) was $79.1 \pm 14.5$ years (interquartile range, 75 to 88 years). The majority (73.2\%) of the patients were female. The most common race was white $(84.5 \%)$, 


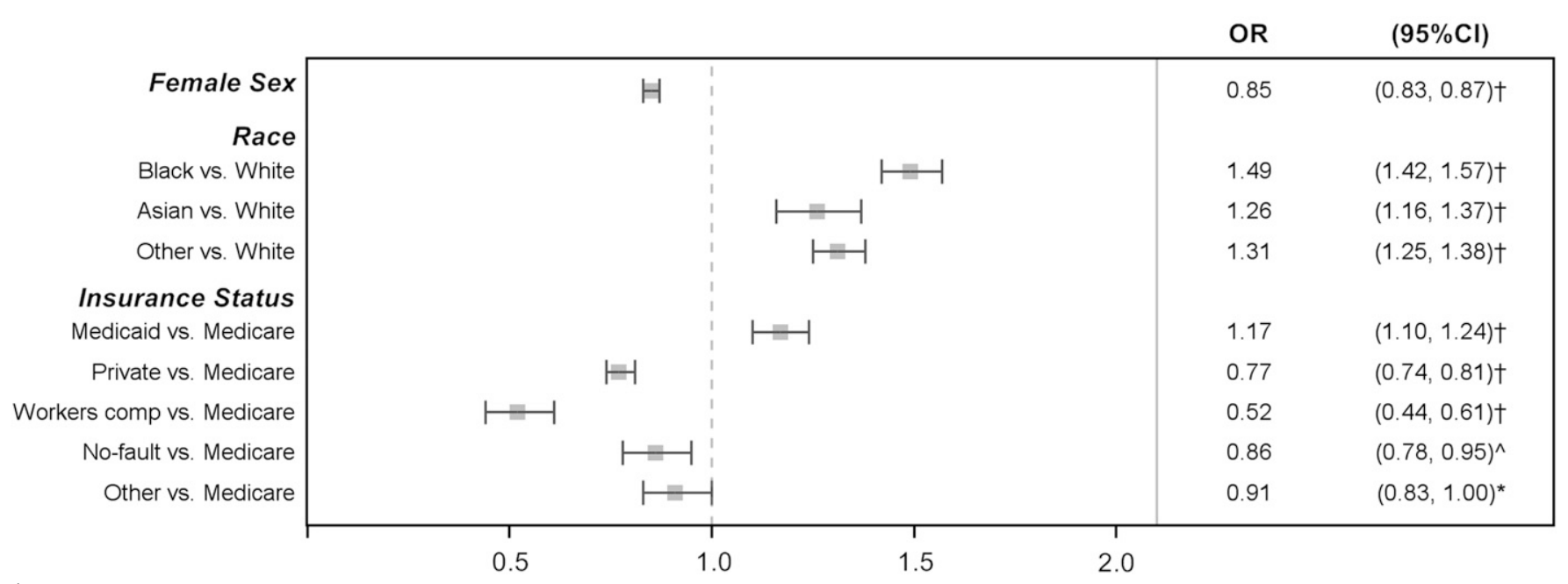

Fig. 1

Patient characteristics associated with delayed hip fracture surgery (multivariable logistic regression model adjusted for characteristics shown and age, Deyo Comorbidity Index, type of surgery, osteoporosis diagnosis present on admission, number of hospitals in hospital service area, number of beds at treating hospital, urban or rural type of treating hospital, teaching status of treating hospital, hospital volume of hip fracture cases, surgeon volume of hip fracture cases, and Area Deprivation Index). *P $<0.05 ; \wedge p<0.01 ; \dagger p<0.001$.

followed by other (4.9\%), black (4.8\%), and Asian (1.7\%). The most common insurance type was Medicare (83.0\%), followed by private $(8.8 \%)$ and Medicaid (3.9\%) (Table I).

The majority of patients (79.8\%) underwent surgery within 2 calendar days after admission. The 90 -day readmission rate was $27.7 \%$. The most frequent complication within 90 days after discharge was catheter-associated urinary tract infection $(9.8 \%$ of all patients), followed by congestive heart failure $(7.5 \%$ of all patients) and pneumonia ( $7.1 \%$ of all patients); overall, $26.6 \%$ of the patients experienced at least 1 complication. The rate of reoperations within 1 year of discharge was 5.3\%, with the most common procedure being irrigation and debridement $(4.6 \%$ of all patients and $36.1 \%$ of the reoperations). In-hospital mortality within 1 year was $7.1 \%$. This outcome includes deaths that occurred during the initial hospital admission and those that occurred during a subsequent hospitalization (in New York State) within 1 year after discharge (see Appendix).

The multivariable logistic regression and Cox proportional hazards models indicated that men and patients with higher Deyo comorbidity scores were at greater risk for delayed surgery (Fig. 1), readmissions (Fig. 2), reoperations (Fig. 3), complications, and 1-year in-hospital mortality (Fig. 4). Older patients were at increased risk for delayed surgery (Fig. 1), readmissions (Fig. 2), complications, and 1-year in-hospital

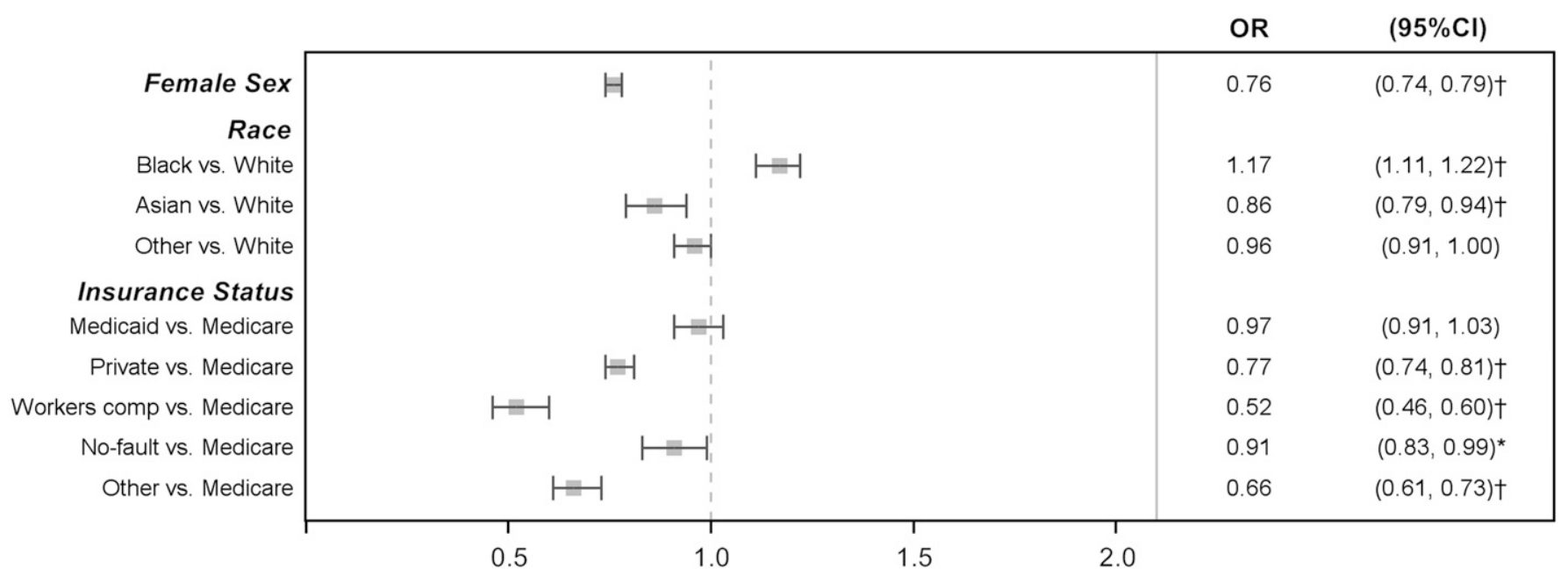

Fig. 2

Patient characteristics associated with readmission within 90 days after hip fracture surgery (multivariable logistic regression model adjusted for characteristics shown and age, Deyo Comorbidity Index, type of surgery, osteoporosis diagnosis present on admission, number of hospitals in hospital service area, number of beds at treating hospital, urban or rural type of treating hospital, teaching status of treating hospital, hospital volume of hip fracture cases, surgeon volume of hip fracture cases, and Area Deprivation Index). $* P<0.05 ; \wedge p<0.01 ; \nmid p<0.001$. 


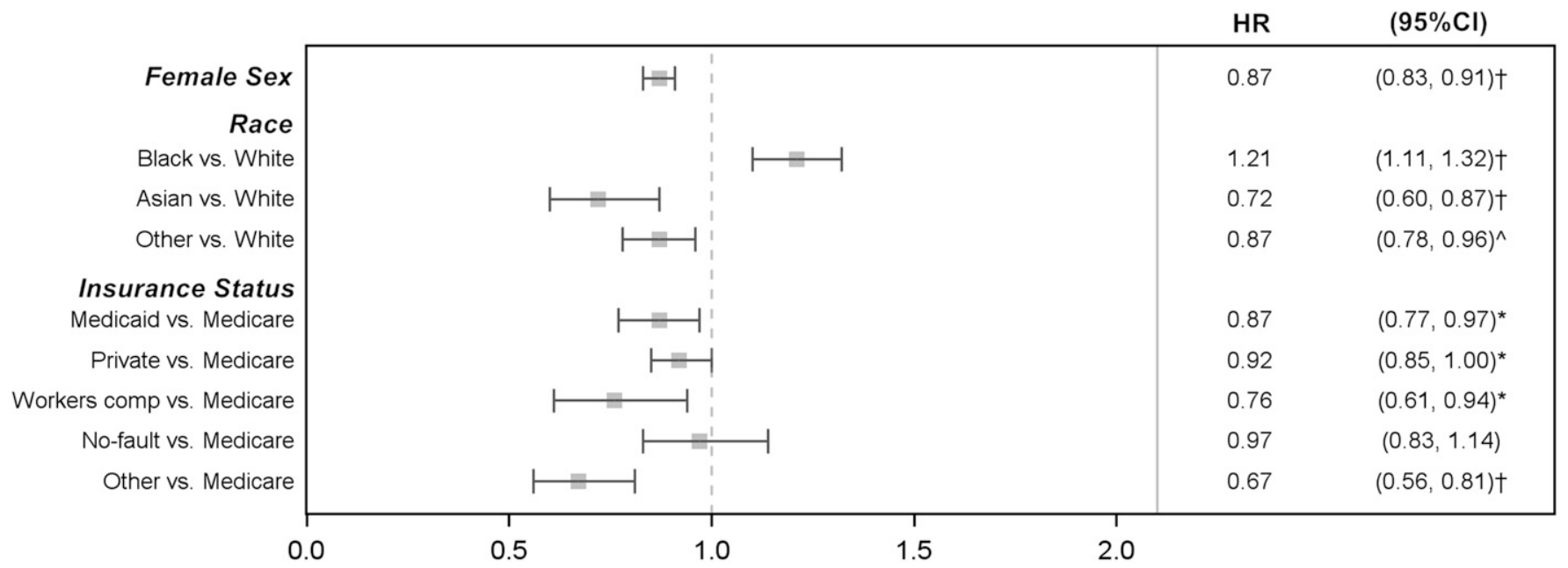

Fig. 3

Patient characteristics associated with a reoperation within 1 year after hip fracture surgery (multivariable logistic regression model adjusted for characteristics shown and age, Deyo Comorbidity Index, type of surgery, osteoporosis diagnosis present on admission, number of hospitals in hospital service area, number of beds at treating hospital, urban or rural type of treating hospital, teaching status of treating hospital, hospital volume of hip fracture cases, surgeon volume of hip fracture cases, and Area Deprivation Index). ${ }^{*} \mathrm{P}<0.05 ; \wedge p<0.01 ; \dagger p<0.001$.

mortality (Fig. 4) but were at decreased risk for reoperations (Fig. 3). After adjusting for patient characteristics, type of surgery, hospital volume and other characteristics, surgeon volume, and Area Deprivation Index, black patients were at greater risk for delayed surgery (odds ratio $[\mathrm{OR}]=1.49 ; 95 \%$ confidence interval $[\mathrm{CI}]=1.42,1.57)$, a reoperation (hazard ratio $[\mathrm{HR}]=1.21 ; \mathrm{CI}=1.11,1.32)$, readmission $(\mathrm{OR}=1.17 ; \mathrm{CI}=1.11$, $1.22)$, and 1-year in-hospital mortality $(\mathrm{HR}=1.13$; $\mathrm{CI}=1.07$, 1.21) than white patients. Black patients were not at increased risk for complications compared with white patients. Compared with white patients, Asian patients were at increased risk for delayed surgery $(\mathrm{OR}=1.26 ; \mathrm{CI}=1.16,1.37)$ but were at decreased risk for a reoperation $(\mathrm{HR}=0.72 ; \mathrm{CI}=0.60,0.87)$ and readmission $(\mathrm{OR}=0.86 ; \mathrm{CI}=0.80,0.94)$ (see Appendix).

After adjusting for patient characteristics, type of surgery, hospital volume and other characteristics, surgeon volume, and Area Deprivation Index, Medicaid patients were at increased risk for delayed surgery $(\mathrm{OR}=1.17 ; \mathrm{CI}=1.10,1.24)$ but at decreased risk for complications $(\mathrm{OR}=0.90 ; \mathrm{CI}=0.84$, $0.95)$ and a reoperation $(\mathrm{HR}=0.87$; $\mathrm{CI}=0.77,0.97)$ compared with Medicare patients. Privately insured patients were at decreased risk for delayed surgery $(\mathrm{OR}=0.77$; $\mathrm{CI}=0.74$, $0.81)$, readmission $(\mathrm{OR}=0.77 ; \mathrm{CI}=0.74,0.81)$, complications $(\mathrm{OR}=0.80 ; \mathrm{CI}=0.77,0.84)$, and 1-year in-hospital

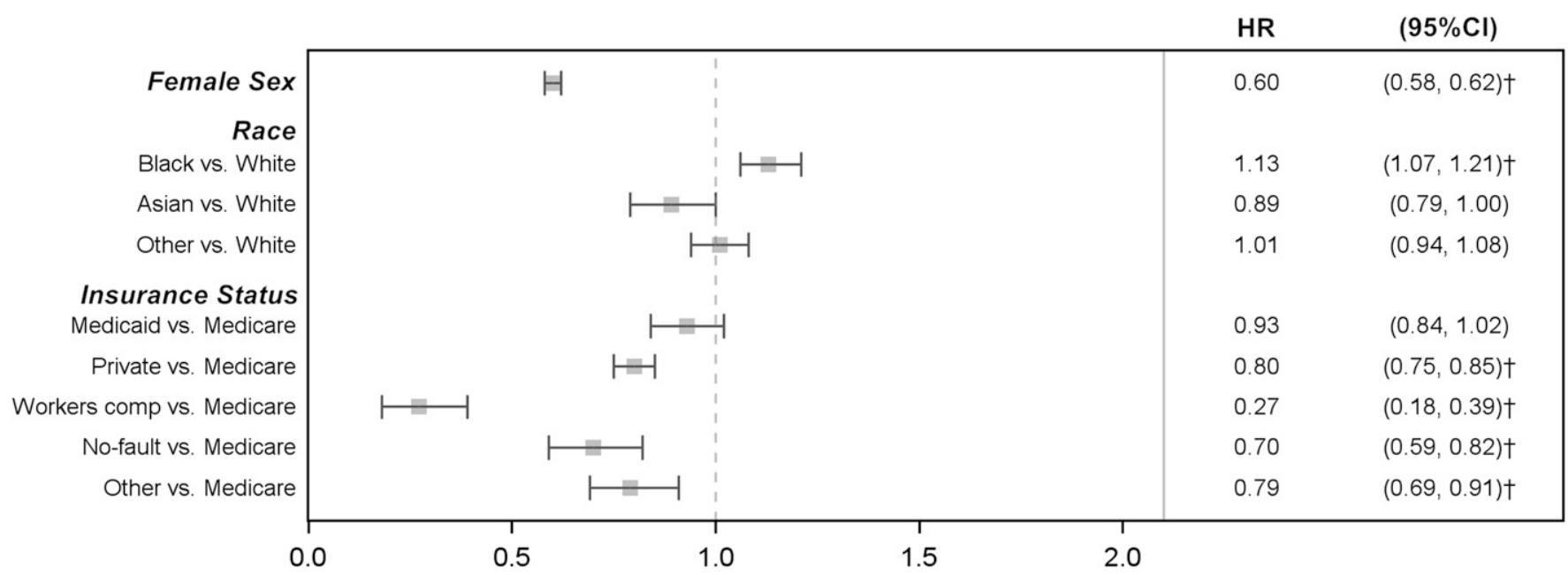

Fig. 4

Patient characteristics associated with inpatient mortality within 1 year after hip fracture surgery (multivariable logistic regression model adjusted for characteristics shown and age, Deyo Comorbidity Index, type of surgery, osteoporosis diagnosis present on admission, number of hospitals in hospital service area, number of beds at treating hospital, urban or rural type of treating hospital, teaching status of treating hospital, hospital volume of hip fracture cases, surgeon volume of hip fracture cases, and Area Deprivation Index). $* P<0.05 ; \wedge p<0.01 ; \uparrow p<0.001$. 
mortality $(\mathrm{HR}=0.80 ; \mathrm{CI}=0.75,0.85)$ compared with Medicare patients.

Our subgroup analyses, which compared patients by race within the same Area Deprivation Index grouping, indicated that black patients were at higher risk for delayed surgery than white patients in all social deprivation quartiles, including the least deprived quartile $(\mathrm{OR}=1.44 ; \mathrm{CI}=1.37,1.52)$, the middle quartiles $(\mathrm{OR}=2.06 ; \mathrm{CI}=1.82,2.32)$, and the most deprived quartile $(\mathrm{OR}=1.44 ; \mathrm{CI}=1.18,1.76)$. Similarly, Asian patients were at increased risk compared with white patients for delayed surgery in all social deprivation quartiles, including the least deprived quartile $(\mathrm{OR}=1.14 ; \mathrm{CI}=1.05,1.24)$, middle quartiles $(\mathrm{OR}=1.55 ; \mathrm{CI}=1.02,2.35)$, and most deprived quartile $(\mathrm{OR}=$ 2.12 ; $\mathrm{CI}=1.22,3.68$ ). There was also an increased risk of 90 day readmission for black patients compared with white patients in all social deprivation quartiles, including the least deprived $(\mathrm{OR}=1.14 ; \mathrm{CI}=1.07,1.20)$, middle quartiles $(\mathrm{OR}=$ 1.32 ; $\mathrm{CI}=1.17,1.48)$, and most deprived $(\mathrm{OR}=1.26$; $\mathrm{CI}=$ $1.06,1.49)$. The occurrence of the other outcome measures (complications, reoperation, and 1-year mortality) was not consistently increased in the black patients across social deprivation groups (Table II).

\section{Discussion}

While national trends indicate overall improvements in hip fracture care ${ }^{2,3}$, we have demonstrated racial and socioeconomic disparities in the delivery of care. After multivariable adjustment, black patients were at significantly greater risk for delayed surgery, a reoperation, readmission, and 1-year in-hospital mortality than white patients. Our subgroup analysis indicated that race-based disparities in delivery of care persist for patients from communities of similar socioeconomic standing. The negative implications of delaying surgery beyond 48 hours after admission are confirmed by our findings and supported by a recent meta-analysis ${ }^{19}$. Our analysis corroborates the finding of Tsai et al. that black patients are at increased risk for postsurgical readmission $^{20}$, but the increased mortality risk for black patients after hip fracture indicates that race-based disparities may have dire consequences. The existing literature on race-based differences in mortality after hip fracture is both limited and conflicting. Penrod et al. ${ }^{6}$ and Lu-Yao et al. ${ }^{12}$ indicated that black patients are at greater risk for mortality, while Jacobsen et al. ${ }^{11}$ did not find a difference in mortality risk. Our findings corroborate the former but are based on a substantially larger sample size with incorporation of multiple payers and additional quality measures in the analysis. Despite an increased risk for delayed surgery, Asian patients were less likely to have a reoperation or readmission than white patients. Although prior studies have confirmed a lower hip fracture risk in Asian-American patients compared with white patients ${ }^{21}$, there has been little investigation of the post-fracture prognosis for this specific ethnicity. While it is possible that genetic differences in osseous microarchitecture, such as those noted in Chinese-American patients $^{22}$, may contribute, it is likely that a multitude of other patient characteristics (e.g., physical attributes, cultural differences, and social determinants of health) more heavily influence post-fracture prognosis and deserve further investigation. The contrasting findings between black and Asian patients emphasize the need for additional study of race/ethnicity and culture-based differences in quality of care.

Our analysis suggests that patients from economically disadvantaged backgrounds (in particular, those with Medicaid insurance) are at increased risk for undergoing delayed surgery for hip fractures. While use of Medicaid insurance as a marker of socioeconomic status is relatively crude, it is the only patientlevel marker of socioeconomic status that is available in our data set. The income-level qualifications required to obtain Medicaid insurance during this study period (before implementation of the Affordable Care Act) accurately reflect lower socioeconomic standing. Lower socioeconomic status has been linked to increased hip fracture risk ${ }^{23,24}$, but the association between socioeconomic factors and post-fracture outcomes is less clear. Studies from the United Kingdom indicate that patients with lower socioeconomic status are at increased risk for 1-year mortality ${ }^{7,8}$, while investigators from the United States did not find an association between socioeconomic factors and mortality after hip fracture ${ }^{10,25}$. The findings of the prior American studies may be related to the use of data from samples of healthy adults with a relatively low number of hip fracture events $(n=730$ in the study by Tosteson et al. ${ }^{10}$ and $\mathrm{n}=495$ in the study by Bentler et $\mathrm{al}^{25}$ ). In addition to the greater statistical power provided by our larger sample of patients with hip fracture $(n=197,290)$, our inclusion of patients with all insurance types increases the generalizability of our findings. The current expansion of the Medicaid program in the United States emphasizes the urgency of exploring ways to mitigate, and eventually eliminate, socioeconomic disparities in hip fracture care. Aside from affecting patients individually, these disparities can drastically impact hospitals and health-care systems. Given that readmissions are increasingly regarded as a quality metric, our findings underscore the need to consider existing disparities during determination of risk adjustment for hospital and provider ratings. Furthermore, the recent emphasis on cost containment in health care has prompted a shift toward value-based payment, with financial penalties for events such as readmission ${ }^{26}$. Given that these payment models may disproportionately affect hospitals that serve vulnerable populations ${ }^{27}$ and exacerbate existing health-care disparities ${ }^{28,29}$, there are multiple incentives for health-care leaders to dedicate resources to understanding and addressing the underlying reasons for disparities.

The 2 primary contributors to health-care disparities are differences among patients and differences in the medical care that they receive $e^{30}$. While we incorporated all relevant patient information that was available to us, detailed analyses of additional characteristics that affect health and health-care utilization, such as social determinants and individual patient preferences, are needed. Additionally, the manner in which medical care is delivered should be further examined. Nonwhite patients are at significantly greater risk of undergoing surgery at low-quality hospital $s^{31,32}$. Investigators from Italy demonstrated that 2 policybased adjustments - public reporting of outcomes ${ }^{33}$ and pay-forperformance compensation-significantly improved the quality 
of care for patients with hip fractures ${ }^{34}$. Both of these principles are present in the United States Affordable Care Act, indicating that strategic implementation of these policies could address disparities in care for patients with hip fractures. More immediately, health-care leaders and providers should consider dedicating resources to process improvement $t^{35}$ and utilizing multidisciplinary teams to improve the quality of acute and post-discharge care ${ }^{36}$.

Our study had the limitations inherent to administrative data, such as the reliance on consistent and accurate entry of complication codes. Inconsistent reporting would have an unclear effect on our findings. A prior audit for complications after hip fractures demonstrated that administrative data had a $67 \%$ sensitivity and $76 \%$ specificity $^{37}$, whereas a recent analysis of total joint replacements showed that the sensitivity of administrative data, with regard to its ability to reflect complications, ranged from $29 \%$ to $100 \%$ and its specificity was consistently $>92 \%{ }^{38}$. A low sensitivity combined with a high specificity would likely result in an accurate but conservative estimate of complications. Additionally, we were unable to capture complications that occurred outside of New York State. We attempted to minimize the effect of this limitation by including only New York State residents in our cohort. We were also unable to capture deaths that did not occur within a hospital in New York State, which led to an underestimation of 1 -year mortality in this study compared with a recent metaanalysis ${ }^{19}$. Furthermore, our reliance on administrative data did not allow us to evaluate the association of individual income and education level with the risk of complications and mortality after hip fracture. While census-based approaches to indirectly measure socioeconomic status have been validated ${ }^{39}$ and have been used in prior orthopaedic utilization studies ${ }^{40,41}$, it would be ideal to evaluate socioeconomic variables on an individual level given their demonstrated influence on outcomes following other types of musculoskeletal trauma ${ }^{42}$. Lastly, the administrative nature of our data did not allow us to include relevant patient-reported outcomes, such as mobility and quality of life, after hip fracture treatment. Despite these drawbacks, using statewide data over a 12-year period allowed us to evaluate a large sample with a demographic composition and payer mix reflective of New York State. Our populationbased results have greater generalizability than single-center or single-payer series and provide data that are useful for counseling patients, designing interventions to address disparities, and informing policymakers.

While recent quality improvement efforts have been effective in improving overall delivery of $\mathrm{care}^{2,3,30}$, there are racial and socioeconomic disparities in the treatment of and outcomes after hip fractures. Notwithstanding their tremendous effect on the lives of patients, these disparities have the potential to substantially affect both hospitals and health-care providers in an era of value-based payment. In addition to detailed investigation into the reasons contributing to disparities in hip fracture care, targeted interventions should be developed to mitigate the effects of these disparities on patients at greatest risk.

\section{Appendix}

eA Tables showing the ICD-9-CM codes used for inclusion and postoperative complications, reoperations, readmissions, and mortality; and patient characteristics associated with hip fracture outcomes are available with the online version of this article as a data supplement at jbjs.org.

Christopher J. Dy, MD, MPH

Joseph M. Lane, $\mathrm{MD}^{2,3}$

Ting Jung Pan, $\mathrm{MPH}^{2}$

Michael L. Parks, $\mathrm{MD}^{2}$

Stephen Lyman, $\mathrm{PhD}^{2,3}$

${ }^{1}$ Department of Orthopaedic Surgery, Washington University School of Medicine, St. Louis, Missouri

${ }^{2}$ Department of Orthopaedic Surgery (J.M.L. and M.L.P.) and Healthcare Research Institute (J.M.L., T.J.P., M.L.P., and S.L.), Hospital for Special Surgery, New York, NY

${ }^{3}$ Weill Cornell Medical College, New York, NY

E-mail address for C.J. Dy: dyc@wudosis.wustl.edu

\section{References}

1. Burge R, Dawson-Hughes B, Solomon DH, Wong JB, King A, Tosteson A. Incidence and economic burden of osteoporosis-related fractures in the United States, 2005-2025. J Bone Miner Res. 2007 Mar;22(3):465-75.

2. Brauer $C A$, Coca-Perraillon $M$, Cutler DM, Rosen $A B$. Incidence and mortality of hip fractures in the United States. JAMA. 2009 Oct 14;302(14):1573-9.

3. Becker DJ, Arora T, Kilgore ML, Curtis JR, Delzell E, Saag KG, Yun H, Morrisey MA. Trends in the utilization and outcomes of Medicare patients hospitalized for hip fracture, 2000-2008. J Aging Health. 2014 Apr;26(3):360-79. Epub 2014 Jan 8. 4. Graham JE, Chang PF, Bergés IM, Granger CV, Ottenbacher KJ. Race/ethnicity and outcomes following inpatient rehabilitation for hip fracture. J Gerontol A Biol Sci Med Sci. 2008 Aug;63(8):860-6.

5. Neuman MD, Fleisher LA, Even-Shoshan O, Mi L, Silber JH. Nonoperative care for hip fracture in the elderly: the influence of race, income, and comorbidities. Med Care. 2010 Apr;48(4):314-20.

6. Penrod JD, Litke A, Hawkes WG, Magaziner J, Doucette JT, Koval KJ, Silberzweig $\mathrm{SB}$, Egol KA, Siu AL. The association of race, gender, and comorbidity with mortality and function after hip fracture. J Gerontol A Biol Sci Med Sci. 2008 Aug;63(8): 867-72.

7. Quah C, Boulton C, Moran C. The influence of socioeconomic status on the incidence, outcome and mortality of fractures of the hip. J Bone Joint Surg Br. 2011 Jun;93(6):801-5.

8. Roberts SE, Goldacre MJ. Time trends and demography of mortality after fractured neck of femur in an English population, 1968-98: database study. BMJ. 2003 Oct 4;327(7418):771-5.

9. Sterling RS. Gender and race/ethnicity differences in hip fracture incidence, morbidity, mortality, and function. Clin Orthop Relat Res. 2011 Jul;469(7):1913-8. 10. Tosteson AN, Gottlieb DJ, Radley DC, Fisher ES, Melton LJ 3rd. Excess mortality following hip fracture: the role of underlying health status. Osteoporos Int. 2007 Nov;18(11):1463-72. Epub 2007 Aug 29.

11. Jacobsen SJ, Goldberg J, Miles TP, Brody JA, Stiers W, Rimm AA. Race and sex differences in mortality following fracture of the hip. Am J Public Health. 1992 Aug;82(8):1147-50. 
The Journal of Bone \& Joint Surgery $\cdot$ JbJs.org VOlume 98-A - Number $10 \cdot$ May 18,2016
Racial and Socioeconomic Disparities in Hip Fracture Care
12. Lu-Yao GL, Baron JA, Barrett JA, Fisher ES. Treatment and survival among elderly Americans with hip fractures: a population-based study. Am J Public Health. 1994 Aug;84(8):1287-91.

13. Dy CJ, Marx RG, Bozic KJ, Pan TJ, Padgett DE, Lyman S. Risk factors for revision within 10 years of total knee arthroplasty. Clin Orthop Relat Res. 2014 Apr;472(4):1198-207. Epub 2013 Dec 18.

14. Deyo RA, Cherkin DC, Ciol MA. Adapting a clinical comorbidity index for use with ICD-9-CM administrative databases. J Clin Epidemiol. 1992 Jun;45(6):613-9. 15. Charlson ME, Pompei $P$, Ales KL, MacKenzie CR. A new method of classifying prognostic comorbidity in longitudinal studies: development and validation. J Chronic Dis. 1987;40(5):373-83.

16. Singh GK. Area deprivation and widening inequalities in US mortality, 1969 1998. Am J Public Health. 2003 Jul;93(7):1137-43.

17. Wennberg JE, Cooper M, Birkmeyer JD, Bonner K, Bubolz T, Campbell D, Fisher E, O'Connor G, Poage J, Sharpe S, Skinner J, Stukel T, Wennberg DE. The Dartmouth atlas of health care in the United States. Chicago: AHA; 1999. 18. Rural Health Research Center. Rural-Urban Commuting Area Codes (RUCAs). 2005. http://depts.washington.edu/uwruca/index.php. Accessed 2015 Jun 3. 19. Moja L, Piatti A, Pecoraro V, Ricci C, Virgili G, Salanti G, Germagnoli L, Liberati A, Banfi G. Timing matters in hip fracture surgery: patients operated within 48 hours have better outcomes. A meta-analysis and meta-regression of over 190,000 patients. PLoS One. 2012;7(10):e46175. Epub 2012 Oct 3.

20. Tsai TC, Orav EJ, Joynt KE. Disparities in surgical 30-day readmission rates for Medicare beneficiaries by race and site of care. Ann Surg. 2014 Jun;259(6):108690.

21. Barrett-Connor E, Siris ES, Wehren LE, Miller PD, Abbott TA, Berger ML, Santora $A C$, Sherwood LM. Osteoporosis and fracture risk in women of different ethnic groups. J Bone Miner Res. 2005 Feb;20(2):185-94. Epub 2004 Oct 18.

22. Walker MD, McMahon DJ, Udesky J, Liu G, Bilezikian JP. Application of highresolution skeletal imaging to measurements of volumetric BMD and skeletal microarchitecture in Chinese-American and white women: explanation of a paradox. J Bone Miner Res. 2009 Dec;24(12):1953-9.

23. Court-Brown CM, Aitken SA, Duckworth AD, Clement ND, McQueen MM. The relationship between social deprivation and the incidence of adult fractures. J Bone Joint Surg Am. 2013 Mar 20;95(6):e321-7.

24. Guilley E, Herrmann F, Rapin CH, Hoffmeyer P, Rizzoli R, Chevalley T. Socioeconomic and living conditions are determinants of hip fracture incidence and age occurrence among community-dwelling elderly. Osteoporos Int. 2011 Feb;22(2):647-53. Epub 2010 May 18

25. Bentler SE, Liu L, Obrizan M, Cook EA, Wright KB, Geweke JF, Chrischilles EA, Pavlik CE, Wallace RB, Ohsfeldt RL, Jones MP, Rosenthal GE, Wolinsky FD. The aftermath of hip fracture: discharge placement, functional status change, and mortality. Am J Epidemiol. 2009 Nov 15;170(10):1290-9. Epub 2009 Oct 4.

26. Centers for Medicare and Medicaid Services. Readmissions Reduction Program. 2013. http://www.cms.gov/Medicare/Medicare-Fee-for-Service-Payment/ AcutelnpatientPPS/Readmissions-Reduction-Program.html. Accessed 2015 Jun 3. 27. Gu Q, Koenig L, Faerberg J, Steinberg CR, Vaz C, Wheatley MP. The Medicare Hospital Readmissions Reduction Program: potential unintended consequences for hospitals serving vulnerable populations. Health Serv Res. 2014 Jun;49(3):818-37. Epub 2014 Jan 13

28. Casalino LP, Elster A, Eisenberg A, Lewis E, Montgomery J, Ramos D. Will pay-for-performance and quality reporting affect health care disparities? Health Aff (Millwood). 2007 May-Jun;26(3):w405-14. Epub 2007 Apr 10.

29. Ryan AM. Will value-based purchasing increase disparities in care? N Engl J Med. 2013 Dec 26;369(26):2472-4.

30. Qasim M, Andrews RM. Despite overall improvement in surgical outcomes since 2000, income-related disparities persist. Health Aff (Millwood). 2013 Oct;32 (10):1773-80.

31. Losina E, Wright EA, Kessler CL, Barrett JA, Fossel AH, Creel AH, Mahomed NN, Baron JA, Katz JN. Neighborhoods matter: use of hospitals with worse outcomes following total knee replacement by patients from vulnerable populations. Arch In tern Med. 2007 Jan 22;167(2):182-7.

32. Dimick J, Ruhter J, Sarrazin MV, Birkmeyer JD. Black patients more likely than whites to undergo surgery at low-quality hospitals in segregated regions. Health Aff (Millwood). 2013 Jun;32(6):1046-53.

33. Colais P, Agabiti N, Fusco D, Pinnarelli L, Sorge C, Perucci CA, Davoli M. In equality in 30-day mortality and the wait for surgery after hip fracture: the impact of the regional health care evaluation program in Lazio (Italy). Int J Qual Health Care. 2013 Jul;25(3):239-47. Epub 2013 Jan 18.

34. Colais P, Pinnarelli L, Fusco D, Davoli M, Braga M, Perucci CA. The impact of a pay-for-performance system on timing to hip fracture surgery: experience from the Lazio Region (Italy). BMC Health Serv Res. 2013;13:393. Epub 2013 Oct 7.

35. Dy CJ, McCollister KE, Lubarsky DA, Lane JM. An economic evaluation of a systems-based strategy to expedite surgical treatment of hip fractures. J Bone Joint Surg Am. 2011 Jul 20;93(14):1326-34.

36. Grigoryan KV, Javedan $\mathrm{H}$, Rudolph JL. Orthogeriatric care models and outcomes in hip fracture patients: a systematic review and meta-analysis. J Orthop Trauma. 2014 Mar;28(3):e49-55.

37. Fox KM, Reuland M, Hawkes WG, Hebel JR, Hudson J, Zimmerman SI, Kenzora J, Magaziner J. Accuracy of medical records in hip fracture. J Am Geriatr Soc. 1998 Jun;46(6):745-50.

38. Bozic KJ, Bashyal RK, Anthony SG, Chiu V, Shulman B, Rubash HE. Is administratively coded comorbidity and complication data in total joint arthroplasty valid? Clin Orthop Relat Res. 2013 Jan;471(1):201-5.

39. Krieger N. Overcoming the absence of socioeconomic data in medical records: validation and application of a census-based methodology. Am J Public Health. 1992 May;82(5):703-10.

40. Skinner J, Zhou W, Weinstein J. The influence of income and race on total knee arthroplasty in the United States. J Bone Joint Surg Am. 2006 Oct;88(10):2159-66. 41. Cram $P$, Vaughan-Sarrazin MS, Rosenthal GE. Hospital characteristics and patient populations served by physician owned and non physician owned orthopedic specialty hospitals. BMC Health Serv Res. 2007;7:155. Epub 2007 Sep 25.

42. Bosse MJ, MacKenzie EJ, Kellam JF, Burgess AR, Webb LX, Swiontkowski MF, Sanders RW, Jones AL, McAndrew MP, Patterson BM, McCarthy ML, Travison TG, Castillo RC. An analysis of outcomes of reconstruction or amputation after legthreatening injuries. N Engl J Med. 2002 Dec 12;347(24):1924-31. 